\title{
Células de Manufatura
}

\section{José Celso Contador}

Professor Livre-Docente

Departamento de Enga de Produção da Faculdade de Engenharia da UNESP

Av. Ariberto Pereira da Cunha, 333 - Caixa Postal 205

12500-000 Guaratinguetá - SP

Tel (0125) $222800 \mathrm{R} 189$

Palavras-chave: produtividade fabril, tempo inativo, piso-de-fábrica, enriquecimento de funções, célula de manufatura.

Key Words: manufacture productivity, inative-time, plant ground, manufacture cell.

\section{RESUMO}

Todos que pensam sobre célula de manufatura entendem-na como algo semelhante à organização celular tipicamente implantada pela Toyota, ou seja, por produto. Nós, entretanto, identificamos quatro tipos de célula de manufatura: por produto com predominância da máquina, por produto com predominância do homem, por processo e por posição fixa do produto. A célula de manufatura por processo, por apresentar três grandes vantagens - proporcionar significativo aumento na produtividade do homem, não requerer operários multifuncionais e ser facilmiente implantada -, é a mais recomendável para o atual estágio da indústria brasileira de manufatura.

\begin{abstract}
Everybody who thinks about manufacturing cell understands it as something similar to the cellular organization typically implanted by Toyota, i.e., per product. However, we identify four types of manufacturing cell: per product with predominance of machine, per product with predominance of the operator, per process and per fixed position of the product. The manufacturing cell per process, by presenting three great advantages - proposes significative increase in the operator productivity, it does not require multifuctional operations, it is easily implanted -, it is most advisable to the present level of the manufacturing Brazilian industry.
\end{abstract}




\section{Tipologia da Célula de Manufatura}

\section{Os Vários Tipos de Célula de Manufatura}

A célula de manufatura, pioneiramente implantada pela Toyota no Japão, consiste numa configuração onde as máquinas são dispostas numa sequiência idêntica à das elapas do processo de fabricação de um produto, ou de uma família de produtos definida segundo o conceito de tecnologia de grupo, e onde, sem estoque intermediário, procura-se, em cada vez, completar o ciclo de produção de uma peça ou produto dentro de uma restrita área de trabalho.

O cxemplo característico é a fabricação e acabamento de uma engrenagem. Um opcrário, apenas, é responsável por 16 máquinas, cada uma com uma função específica. Ele retira da primeira máquina a peça já processada, coloca a peça a ser processada, apanha a peça antcrior c encaminha-se para a segunda máquina, acionando a chave siluada entre as duas máquinas para pôr em movimento a primeira máquina. Na segunda máquina, ele retira a peça já processada, coloca a que trouxe da primeira máquina, apanla a processada $\mathrm{c}$ encaminha-se para a terceira máquina, acionando a clave para ligar a segunda máquina. Repete esse procedimento nas 16 máquinas, dispostas $\mathrm{cm}$ forma de $\mathrm{U}$, completando o ciclo em 5 minutos, o que significa que a cada 5 minutos uma engrenagem está pronta (IMAM, 1989).

Todos que pensam sobre célula de manufatura e todos autores que dela tratam cntendem por célula de manufatura algo como o conceituado, ou seja, "uma fábrica dentro da fábrica". Vejam-se, por exemplo, oito autores (BEZERRA, 1990; HALL, 1988; IMAM, 1989; MONDEN, 1984; MOURA, 1989; OLIVÉRIO, 1984 ; SCHONBERGER, 1984; YOSHINAGA, 1988).

Entrelanto, nós identificamos quatro tipos de célula de manufatura: por produto com predominância da máquina, por produto com predominância do homem, por processo e por posição fixa do produto (CONTADOR, 1991). Pelas denominações, percebe-se que foram classificados analogamentc aos tipos clássicos de layout.

A célula de manufatura por produto com predominância da máquina corresponde ao modelo da Toyota recém descrito, que ć o tipo reconhecido por todos.

A célula de manufatura por produto com predominância do homem é semelhante à anterior, onde os postos de serviços são dispostos na sequiencia das etapas do processo de fabricação de um produto ou familia de produtos, de forma a completar pelo menos parte da fabricação de uma peça ou produto numa área restrita. Serve como exemplo o acabamento de peças fundidas pela execução sequiencial de três operações: rebarbação, lixação e esmerilhação realizadas por um ou por três operírios.

A cćlula de manufatura por processo corresponde ao agnıpamento de operações rcalizadas por máquinas de mesmo tipo, como por cxemplo três fresadoras operadas 
por 1 m mesmo homem. Pode ser denominada também célula funcional, por agregar máquinas que têm a mesma função.

A célula de manufatura por posição fixa do produto é caracterizada pelo agnupamento de operários que trabalham em volta de um produto colocado numa posição fixa. É o modelo implantado pela Saab-Scania na fábrica de motores de Sodertalje na Suécia, onde um grupo de três operários montam um motor colocado sobre uma bancada. Corresponde lambém ao que a Volvo denominou grupo semi-autônomo (HILLESHEIM, 1988). Como este tipo de célula foi implantado c desenvolvido pioneiramente na Suécia, pode ser denominado célula sueca ou escandinava, ou, seguindo a tradição do layout, por célula posicional.

As células de manufatura ainda podem scr classificadas:

a) cm função da quantidade de modelos de produto que processá (um só modelo, uma familia de produtos ou qualquer produto);

b) em função da quantidade de operários que nela trabalha (cćlula individual ou célula grupal com vários operários); c

c) em função da predominância sobre o traballıo, cxercida pela máquina ou pelo homem.

\section{Célula de Manufatura por Produto com Predominância da Máquina}

Josć Luiz Olivério faz algumas recomendações interessantes sobre a célula de manufatura por produto a ponto de merecer citação. "A localização de cada posto de trabalho deve possibilitar adequada visualização dos demais postos, bem como permitir uma visão completa do processo produtivo. Deve permitir que cada atividade conlieça as outras e o todo onde a atividade se localiza. Cada operador deve ter condições de livremente comunicar-se com os demais operadores que participam da fabricação do produto. Deve induzir a uma integração de cada posto de trabalho no processo completo. O objetivo é realmente formar "células de manufatura", onde o conjunto de postos de trabalho possui o mesmo objetivo final. Ao mesmo tempo, o arranjo físico deve permitir que um determinado posto de trabalho conheça a sua parcela do todo, saiba como a sua parte está sendo executada no contexto do processo completo, conlieça como os demais postos de trabalho excculam as suas partes facc ao lodo, de tal forma que, na ocorrência de dificuldades em $\mathbf{l}$ m determinado posto de trabalho, o mesmo possa ser auxiliado por outro, visando o funcionamento eficiente da célula. Para tanto, as distâncias entre os postos de trabalho devem ser mímimas, o que reduz o custo do transporte da produção e confere maior flexibilidade à célula, no caso de ser necessário modificar o seu número de operadores em função das variações na demaunda de fabricação" (OLIVÉRIO, 1984).

"A solução celular pode ser usada quando a produção se referc a um único produlo, ou a vários produlos que constituem uma única família. O que caracteriza a formação da família dc 
produtos, no tocante ao arranjo, é a semelhança ou a identidade do processo produtivo utilizado na fabricação" (OLIVÉRIO,1984).

"Assim, mesmo quando se tratar de produção sob encomenda, não se pode concluir pela inviabilidade do uso do layout celular, sem antes ser feita uma pesquisa da existência da família de peças, componentes, produtos etc. Sendo as famílias identificadas, pode-se, então, decidir pelo uso desse arranjo, em função das vantagens que apresenta. A solução celular pode ser usada, portanto, para produtos seriados ou não seriados, para produtos padronizados, para produção em lotes ou produção sob encomenda, desde que o produto único ou a familia de produtos representem um volume de produção adequado" (OLIVÉRIO, 1984).

"No tocante à quantidade, é importante que o volume de produção, e por decorrência a carga de trabalho sobre os equipamentos, seja suficiente para possibilitar a implantação de um arranjo celular especializado naquele produto único ou na família de produtos" (OLIVÉRIO,1984).

"Quanto aos rotciros, ou seja, os processos produtivos e seus procedimentos e padrões, para o uso do arranjo celular, é importante que haja fluxos dominantes, como os existentes no caso de um único produto ou de uma família de produtos. Este requisito é de suma importância para o sucesso do uso do layout celular. No caso de familias, por exemplo, é importante que todos os seus componentes possuam os mesmos (oul quase os mesmos) processos de fabricação, em sequiência de fases idênticas ou semelhantes. Em outras palavras, quanto aos roteiros, é importante certificar-se de que há repetições na sequiência das operações. Em paralelo, os padrões de tempo devem possibilitar um adequado balanceamento ou nivelamento, entre as operações, principalmente no tocante às máquinas chaves" (OLIVÉRIO, 1984).

O grande inconveniente da célula por produto é a necessidade de mão-de-obra versátil, ou seja, de operador multifuncional, capaz de executar com habilidade e eficiência um grande número de operações. As empresas, de um modo bastante geral, não dispõem desse tipo de operário, e treiná-lo para tanto demanda tempo longo.

\section{Célula de Manufatura por Produto com Predominância do Homem}

Este tipo de célula tem as mesmas características do anterior, com a diferença de ser o trabalho humano o predominante.

Cabe aqui discutir um aspecto muito importante que afeta diretamente a produtividade: é preferível célula individual, onde um único operário trabalha, ou célula grupal, onde vários trabalham?

Um caso real é sugestivo, e sua conclusão pode ser generalizada: a célula individual é superior à grupal na maioria dos fatores considerados, mas exige operador multifuncional. 
Serão comparadas três situações: a antiga, operando segundo o layout clássico por processo; a célula com um homem; c a célula com três homens.

O objeto do estudo são três operações realizadas num setor de acabamento de peças fundidas cm alumínio:

$1^{a}$ operação: rebarbação grossa, utilizando talhadeira pneumática $\mathrm{c}$ fixando a peça numa morsa;

$2^{a}$ operação: lixação, utilizando uma politriz com lixa de fita c segurando a peça com as mãos; $c$

$3^{\text {a }}$ operação: esmerilhamento, utilizando esmerilhadeira pneumática com uma fresa na ponta, havendo fresas de formas adequadas a cada tipo de peça, $\mathrm{c}$ apoiando a peça numa bancada ou prendendo-a numa morsa.

Pelo método antigo, cada uma das operações era cxeculada por um operírio trabalhando $\mathrm{cm}$ seu próprio local. As operações eram feitas $\mathrm{cm}$ lotes de peças, de maneira independente cntre si. Ou seja, o rebarbador terminava seu lote e levava o cesto de peças para o depósito de peças em processo. Quando o lixador terminava outro lote, ia apanhar o cesto das peças cm questão para lixá-las. E assim sucessivamente. No esquema de célula individual, o operário passou a cxecutar as três operações na mesma peça. A bancada, com a talhadeira, a esmerilhadeira $\mathrm{c}$ a morsa, foi colocada perpendicularmente à lixadeira politriz. No esquema de célula grupal, com três homens, cada um continua responsável por uma operação. Assim, o rebarbador apanha uma peça no cesto, rebarba-a c passa-a a lixador, que lixa-a e entrega-a ao csmerilhador, que esmerilha-a c coloca-a no cesto de peças acabadas.

A análise consistirá numa comparação quantitativa, relativa à produtividade, $\mathrm{c}$ numa comparação qualitativa, relativa a vários fatores.

\section{Comparação Quantitativa das Produtividades}

A tabela 1 mostra os ganhos (c perdas) de produtividade devidos a vários fatores, compeurando os dois tipos de ólluł com o método antigo.

O aumento de $9 \%$ na produtividade obtido pela célula individual permitiria uma

\begin{tabular}{|c|c|c|}
\hline AUMENTO DE PRODIJTIVIDADE DEVIDO Aं. & $\begin{array}{l}\text { CÉLULA } \\
\text { I } 110 \mathrm{OMEM}\end{array}$ & $\begin{array}{l}\text { CÉLUL, A } \\
3 \text { HOMENS }\end{array}$ \\
\hline a) sconomia no manuscio das peças & $5 \%$ & $2 \%$ \\
\hline $\begin{array}{l}\text { b) execuçào na lixadeira de suboperaçōes que } \\
\text { nomalmente sio feitas com talhadeira ou } \\
\text { csmerilhadcira (a lixadeira politriz. é mais eficiente) }\end{array}$ & $3 \%$ & - \\
\hline $\begin{array}{l}\text { c) eliminação do percurso da peça devido à reduçảo de } \\
\text { dıas bancadas para uma }\end{array}$ & $1 \%$ & \\
\hline 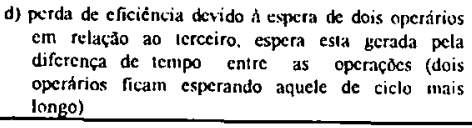 & - & $(29 \%)$ \\
\hline GANHO (PERDA) TOTAL DE PRODUTIVIDADE: & $9 \%$ & $(27 \%)$ \\
\hline
\end{tabular}

Tabela 1 - Comparação Quantitativa entre Célula Individual e Célula Guupal 
redução do quadro de operários de $8 \%$ $(1:(1+0,09)=0,92)$.

A perda de $27 \%$ na produtividade, acarretada pela célula gnupal em relação ao método antigo, implicaria num aumento de $37 \%$ no quadro de opcrários $(1:(1-0,27)=1,37)$.

Deve-se ressaltar que, sc o operário da célula individual não desempenhar com cficiência as três operações, o ganho de produtividade em relação ao método antigo pode desaparecer. Exigir o adestramento da mão-de-obra em múltiplas funções é una constante na célula por produto. E este treinamento nem sempre ć fácil c rápido.

\section{Comparação Qualitativa}

Para a comparação qualitativa, foram selecionados os nove fatores mostrados na tabela 2. A coluna do mcio mostra os resultados da comparação da célula individual com o método antigo. A coluna da dircita mostra os resultados da comparação da célula gnıpal com a célula individual.

\section{Célula de Manufatura por Processo}

A célula de manufatura por processo é caractcrizada pelo agrupamento de duas ou mais máquinas de mesmo tipo, operadas por $\mathrm{um}$ úllico homem c dispostas convenientemente de forma a minimizar os deslocamentos do operador, como, por cxemplo, duas fresadoras, duas coquilhadeiras para fundição.

A finalidade precípua desta célula é aproveitar o tempo-máquina, durantc o qual o operador fica parado esperando a máquina completar automaticamentc scu ciclo. O operário pode, portanto, opcrar outra máquina durante o tempo automático

\begin{tabular}{|c|c|c|}
\hline rATOKR & $\begin{array}{l}\text { CLLUULA DE I HOMEM HM } \\
\text { REIACAAOA AOMETODO ANTICOO }\end{array}$ & 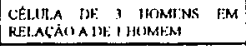 \\
\hline UIIAL,IIIAIF, IN) FRENYITU & $\begin{array}{l}\text { auments, moqux o responcivel te } \\
\text { identifiedvel }\end{array}$ & $\begin{array}{l}\text { diminui, porque dalui roprou. } \\
\text { stabilidade }\end{array}$ \\
\hline FIUIIFY UA I'KODUCAO & $\begin{array}{l}\text { aunienta, gois produtisidale } t \\
\text { maior, kede que se aloque } 3 \\
\text { cétulas por modelo de peta }\end{array}$ & $\begin{array}{l}\text { diminui, pois promituividade d } \\
\text { menor. desde que sejis alocada i } \\
\text { célula par mosto de pesja }\end{array}$ \\
\hline ESTOOUE LMIROXTESO & $\begin{array}{l}\text { Uiminui. pois produtividade } \\
\text { maior }\end{array}$ & $\begin{array}{l}\text { mumenia, pois produtividide e } \\
\text { nuenor }\end{array}$ \\
\hline FACIIDADE PARA F'ROKJRAMAR & 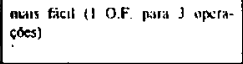 & 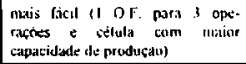 \\
\hline $\begin{array}{l}\text { AlMMINISIKAÇAO PELEI KNCAR. } \\
\text { REGANDO }\end{array}$ & $\begin{array}{l}\text { racalita devido rápida vissusti-zacto } \\
\text { de problentas }\end{array}$ & $\begin{array}{l}\text { diticulta, porque sabs } 3 \text { hornens a } \\
\text { sufierisionar }\end{array}$ \\
\hline DESL.CCAMENTO DE WESSOA. & Mo hit necessidads: & 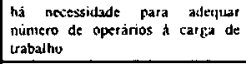 \\
\hline TKLINAMENTIS & $\begin{array}{l}\text { Cxige. pors operário pruseiss ser } \\
\text { mulifuncıolual }\end{array}$ & Moto exige \\
\hline ARE $\wedge$ & exige nıaior área & exige menor arca \\
\hline QUANTIDAISE IJF ROQTH'AMH'NIT & exige niaior quantidade & $\begin{array}{l}\text { exige menor quantidide (mas mais } \\
\text { que antipimente) }\end{array}$ \\
\hline
\end{tabular}

Tabela 2- Comparação Qualitativa entre Célula Individual c Célula Grupal 
da primeira. Está implícito que o ciclo de operação é comandado pela máquina.

Esta cćlula permitc a fabricação de qualquer tipo de produto independentemente de fazerem parte da mesma familia no conccito tradicional. Mas, na realidade, as peças a serem traballadas simultancamente devem pertencer à familia definida pelo conceito de ciclo de operação: a duraçĩo dos ciclos deve ter valores próximos entre si.

A produlividade do operário pode aumentar significativamente, dependendo da relação entre o seu tempo de atividade $\mathrm{c}$ a duração do ciclo total. Sc o opcrário trabalhar simultancamente $\mathrm{cm}$ duas máquinas, se seu tempo de atividade for menor do que a duração do ciclo tolal e se a duração dos ciclos de cada peça tiver valores próximos, a produtividade do operário chegará a dobrar. Entrctanto, a produtividade da máquina de menor ciclo diminuirá, pois scu ciclo ficará igual ao da outra máquina, ou scja, ela terá que csperar csia, perdendo porlanto produlividade.

Para obter-se ganhos significativos de produtividade, ć necessário definir, a partir da anúlise do ciclo de operação, os pares ou ternos de peças a serem processadas simultaneamentc. Ou seja, as familias de peças serão detcrminadas pelo ciclo de opcração. Para tanto, a técnica a ser utilizada é a da carta de atividades múltiplas.

Os critćrios para a constituição da célula de manufatura por processo c para a definição dos produtos a fabricar scrão discutidos posteriomente neste artigo.

A célula de manufatura por processo apresenta três vantagens cxtremamente importantes: proporciona significativo aumento da produtividade do homem, não requer operários multifuncionais e é muito fácil de scr implantada.

Os ganhos de produlividade propiciados ao homem são impressionantes: numa usinagem, 160\% (conforme relatado na aplicação real); numa coquilharia, $60 \%$ (conforme as considerações finais); numa macharia. $52 \%$ (conforme as considerações finais).

A segunda vantagem está cm não requerer operários multifuncionais. Como cada operírio trabalhará sempre no mesmo proccsso, não há necessidade de novo treinamento. (O fresador continuará operando fresadoras, só que duas ou três, ao invés de uma).

A terceira vantagem é a facilidade de implantação. Não há necessidade de treinar opcrários, c a mudança da posição das máquinas é simples: basta dispô-las tangencialmente a um circulo aberto que facilite a cutrada e a saida de peças Obviamente deve haver espaço dentro da célula para cestos com peças a processar $\mathrm{c}$ com peças processadas.

Apcsar de a Toyota, pelas razões a serem cxpostas postcriormente, rejeitar a célula de manufatura por processo. nós. diante destas três vantagens. a recomendamos, de forma enfátical para a fase inicial de um programa de aumento da produlividade fabril. 


\section{Célula de Manufatura Posicional}

A célula posicional ou por posição fixa do produto ć caracterizada pela colocação do produto numa posição fixa, à volta do qual um gnupo de operários trabalha. É o modelo implantado pela Saab-Scania na fábrica de motores de Sodertalje na Suécia, pelo qual, um grupo de três operárias montam um molor, colocado sobre uma bancada, cm meia hora.

Esta cxpcriência da Saab-Scania teve início cm 1969, quando a empresa c o sindicato de seus cmpregados começaram a discutir novos principios para o plancjamento do trabalho. Os objctivos iniciais dessas discussões cram, cm resumo, cinco:

a- dar a todos os empregados melhores oportunidades para opinarem sobre seu próprio traballıo c sobre sua participação no processo de produção;

b- tornar o trabalho industrial mais estimulante c atracnte;

c- reduzir aš possiveis paralisações c conflitos cntre homem e trabalho na linha de montagem;

d- incentivar a eficiência global da produção (produtividadc) por meio da maior flexibilidade e adaptabilidade do traballo industrial às variações de produlo c de demanda; c

c- avaliar os resullados do aumento de produtividade e da salisfação do trabalhador após as mudanças-piloto $\mathrm{cm}$ cada tarefa.

A experiência foi se descnvolvendo semprę com a colaboração do operário, por meio de críticas, idéias c sugestões, c, após algum tempo, surgiu a necessidade de alterar a organização do trabalho no âmbito gerencial da cmpresa, criando dois grupos, um de produção $c$ outro de desenvolvimento. $O$ grupo de produção cstaria voltado para o trabalho concreto de fabricação c montagem. O grupo de desenvolvimento, ou plancjamento, visaria a cooperação cotidiana cutre gerentes, operários c cspecialistas (psicólogos, sociólogos, cconomistas c outros).

O grupo de produção ou célula de manufatura rcúnc de três a cinco operários produzindo os itens $\mathrm{cm}$ fase final de fabricação, um diferencial ou um motor completo. O trabalho ć cxecutado por um dos operários ou por todos cles cm conjunto, conforme acordo estabelecido pelos membros do grupo. As tarefas são sempre disculidas c podem mudar de ordem c de cxecutante. Os objetivos do trabalho podem ser ampliados. As técnicas podem ser melhoradas por sugestão dos participantes. A ordem c a limpeza são fruto da colaboração de todos. Há intercâmbio espontânco ou rodízio acertado pelos próprios membros para a cxecução das larefas. E. finalmentc, o grupo pode auto-organizar-sc, ou seja, os operários podem escolher seus companheiros de traballo, formando equipes mais integradas, cm função de afinidades commus e de adequação ao ritmo das tarcfas.

O grupo de desenvolvimento seria, como de fato foi, constituido básica $\mathrm{c}$ genericamente por $\mathrm{um}$ lider (gerente), um 
cngenheiro industrial, um projetista de ferramentas, um abastecedor de materiais e um ou dois clementos de cada gnupo de produção (célula de manufatura) que está subordinado ao líder. O objetivo principal deste grupo de desenvolvimento ć apoiar os grupos de produção $\mathrm{e}$ permitir que suas cxpcrichcias scjam continuamentc melhoradas c ampliadas. As idćias c sugestões podem nascer dentro do próprio grupo ou vir de fora. Os problemas que não puderem ser resolvidos imediatamente, e são muitos, passam a ser pesquisados, analisados c discutidos. Um grupo de descnvolvimento atende vários grupos de produção.

Enll meados da década de 70, a Volvo fez, na fábrica de automóveis de Kalman, Sućcia, cxperiĉncia semelhante, que, na opinião de Mats-Ola Palm, presidente da Volvo do Brasil Motores c Veículos SA., constituiu "uma das iniciativas pioneiras, no setor automobilístico, $\mathrm{cm}$ administração c produção participativas... com o objetivo de oferecer ao trabalhador algo mais do que seu salário: ambiente de trabalho mais adequado, maior diversificação de tarefas, maior responsabilidade sobre a qualidade $c$ um envolvimento ativo nos processos de decisão" (HILLESHEIM, 1988).

Diante dos bons resultados dessa cxperiência, a Volvo amplioula na fábrica de aufomóveis de Uddevalla, resultando nos denominados gnupos semi-autônomos, um avançado sistema de trabalho participativo que interfere na estnutura do poder, altera as relações entre as pessoas, inclusive as hicrárquicas, c modifica conccitos e comportamentos.
Scgundo Hillesheim c Cosmo (1988), "os grupos scmi-autônomos são grupos de empregados, articulados entre si através de representantes, que se responsabilizam por um conjunto de tarefas interdependentes, previamente agnupadas, que conduzam a um produto final identificável c significativo, alterando-sc o layout de tal forma que aquelas tarcfas possam ser exccutadas $\mathrm{cm}$ um sistema de rodizio".

O grupo semi-autônomo, sendo um sistema participativo, assim como a célula de manufatura por produto, não são fáccis de serem implantadas porque, entre outras razões, cxigem operários multifuncionais, só oblíveis após longo periodo de treinamento.

Apesar de as cxperiências da Volvo terem alcançado resullados auspiciosos, alguns as vêem com ceticismo. John Krafcik, consultor do International Motor Vchicle Program do Instituto de Tecnologia de Massachusetts, que já estudou 80 fábricas automobilísticas, é dc opinião que, "não obstante ser possivel atingir um alto nivel de qualidade, Uddevalla não conscguirá alcançar a produtividade de um sistema razoavelmente eficiente de produção $\mathrm{cm}$ massa japonçs ou nortc-americano" (KAPSTEIN, 1989).

Entretanto, aplicar o conccito de grupo scmi-autônomo, denominado aqui célula de manufatura posicional, deve ser tentado para minimizar o manuscio $\mathrm{c}$ o transportc de peças de grande porte. Portanto, o objetivo ć diferente do da Volvo: reduzir manuscio $c$ transporte $c$ não reduzir monotonia. Nos casos de peças de difícil 
manuscio c transporte, o deslocamento de operários para junto da peça imóvel permite aumento de produtividade is vezes significalivo.

\section{Célula de Manufatura por Processo}

\section{Célula por Processo versus Célula por Produto da Toyota}

A Toyola rejcita o lipo de célula por processo porque "como a quantidade de produção por opcrador aumenta, o inventário de semi-acabados ou estoque intermediário produzido $\mathrm{em}$ cada cslação também aumenta, dificultando o balanccamento da produção cntre as várias eskações... Além disto, os operadores ficam separados, não pennitindo que se auxiliem mutuamente, o que dificulta também o balaunceamento da produção entre os vários processos, surgindo pois inventários desnecessírios entre cles" (MONDEN. 1 984).

Para climinar esses problemas, a Toyota adota a célula de manufatura por produto em forma de $\mathrm{U}$, justapondo várias delas. Com este esquema, um operador pode ir trabalhar na célula contígua para cxccutar algumas das opcrações dela, ou pode receber auxílio do operador vizinho. Ou scja. o operador precisa saber operar todas as máquinas da sua célula $\mathrm{c}$ também as das cćlulas contiguas. Esta cxigência se deve à forma como a Toyota sincronizal a produção à demanda. Dividindo as horas íteis disponiveis diárias pela demanda, detcrmina o tempo do ciclo de produção de cada peça, de cada conjunto, de cada produto. Supondo que o ciclo seja de 1 minuto. cada operador trabalha na sua célula c completa cada peça ou cada conjunto cm I mimuto. (ou múltiplo de I minuto, se houver várias células). Se a demanda cair $16 \%$ por exemplo, o ciclo aumentará $20 \%$, sendo portanto necessário tcrminar uma peça $\mathrm{cm}$ 1,2 minuto. Dispondo de mais tempo, o operador de uma cćlula concluirá seu trabalho $\mathrm{c}$ traballuará 0,2 minuto na célula contigua. Desta forma, cinco opcrários cxccularão o trabalho de seis células, o que significa que unn operário em cada scis é retirado dia produçĩo (MONDEN, 1984).

O sistcma Toyota reduz o estoque em processo c sincroniza a produção à demanda. Sem dúvida é recomendável. Mas cxige um nível altíssimo de organização da produção nos seus mais diversos aspectos. Portanto, sua implantação é muito difícil para o atual estágio da indústria brasilcira.

Por csta razão, não obstantc reconhecermos como corrclas as objeções da Toyota, recomendamos, para o cstágio inicial, a adoção da célula de manufatura por processo devido à não cxigência de operadores multifuncionais, à facilidade de sua implantação c ao significativo aumento de produtividade que gera.

\section{Tecnologia de Grupo}

A indústria manufatureira, de um modo geral. traballha com centenas ou milhares de itens, ell termos de quantidade de peças a fabricar, de matcriais a comprar, dc 
matcriais a cstocar, de operações a cxecutar, de operações a custear, de operações a programar, de ferramentas a controlar ctc..

Como Iratá-los individualmente é scmpre muito trabalhoso, procura-se simplificar sua abordagem pela redução da quantidade. Uma das formas ć considerar apcnas os itcns mais importantes, desprezando os outros; para tanto, o instrımento adequado ć o gráfico $\mathrm{ABC}$ das porcentagens acumuladas, que os classifica segundo critérios apropriados a cada situação. Mas, cm muitos casos, não é possivel simplificar por mcio da desconsideraç̃̃o de muitos itens, uma vez que todos eles precisam ser apreciados. Nestc caso, o instnumcnto a utilizar ć a tecnologia de grupo.

A tecnologia de gnupo segrega os itens cm familias, reunindo numa mesma família lodos os itcns que possucm certas características idênticas ou semelhantes. Daí cm diante, ao invés de tratar individualmente cada item, passa-se a trabalhar com as familias de itens. considerando todos os integrantes de uma familia como um só. Por esta razĩo, ć de fundamental importância definir as características que identificarão cada item com sua familia.

Estas caractcrísticas variarão $\mathrm{cm}$ função do problema a ser resolvido. Para dimensionar embalagens de produtos, por cxcmplo, o critćrio de definição das familias leva $\mathrm{cm}$ consideração a forma $\mathrm{c}$ as dimensões do produto. c pode levar $\mathrm{cm}$ consideração também a natureza do produto com a finalidade de imprimi-la na cmbalagem. É o caso de cmbalagens de produtos pneumáticos: os 320 tipos difcrentesdeválvulas(artigos)puderamser agrupados cm 14 famílias, o que significa que com apenas 14 tamanhos de caixas embalavam-se os 320 tipos de válvulas pneumáticas; e os 400 tipos diferentes de cilindros pneumáticos foramagregadosem 23 famílias para fins de embalagem.

Se a finalidade da segregação for definir famílias de aplicação do produto, o critério scrá outro. Assim, usando os mesmos produtos pneumáticos como cxcimplo, os 320 tipos diferentes de válvulas puderam ser agnupados $\mathrm{cm} 33$ famílias, cm função da vazão de ar (diâmetros de 1/8", 1/4", 3/8", 1/2" c 3/4"), em função das características operacionais (válvula básica, de acionamento mecânico ou muscular, de acionamento pneumático, de acionamento clétrico, de fluxo) e ainda os tipos normalizados pela ISO c uma classe de válvulas diversas.

Como se depreende do exposto, a tecnologia de grupo é o insirumento adequado para a definição das células de manufatura, definição esta que consiste cm determinar a quantidade de células, as máquinas que integrarão cada célula, a quantidade de operários que trabalhará cm cada célula e os produtos que serão processados cm cada célula.

Se a tecnologia de gnupo ć o instrumento adequado, torna-se necessário estabelecer o critćrio de definição das familias. $O$ único critćrio que interessa para a definição das cćlulas de manufatura ć o processo de fabricação. 
Peças podem ter os formatos mais diversos possíveis, dimensões variando entre limites largos, serem constituídas por materiais distintos, c, mesmo assim, pertencerem a uma mesma família desde que a sequiencia das etapas do seu processo de fabricação scja idêntica ou similar.

A geometria das peças é, de um modo geral, bom indicador das semelhanças entre os processos de fabricação, mas podem induzir a enganos. Sc a segregação pelo formato seria mais simples, o criténio mais seguro, apesar de mais trabalhoso, é o do processo de fabricação quanto ì similaridade das máquinas $c$ das ferramentas utilizadas c quanto a similaridade da sequiência das ctapas de fabricação.

O procedimento para definição das células pode ser resumido em cinco elapas:

1) identificar todas as máquinas c cquipamentos análogos quanto à função (como tornos universais, tornos revólveres, furadeiras de bancada, furadeiras de coluna, ctc.) definindo, pois, famílias de máquinas c cquipamentos;

2) identificar, por inspeção visual, todas as peças que, pelo seu formato, possuem indubitavelmente o mesmo processo de fabricação (como parafusos, cixos, engrenagens cilíndricas, engrenagens helicoidais etc.) definindo. pois, conjuntos de peças idênticas quanto ao processo de fabricação;

3) a partir da pré-definição de máquinas c cquipamentos análogos $\mathrm{e}$ da pré-definição do conjunto de peças idênticas quanto ao processo de fabricaçĩo, montar uma matriz biaxial, relacionando cada grupo de máquinas ou equipamentos análogos numa coluna c cada conjunto de peças idênticas numa linla;

4) indicar, no corpo da matriz, a sequiência do processo de fabricação de cada conjunto de peças (na linha de um conjunto de peças, anotar o número 1 na coluna daquela máquina que cxecuta a primcira opcração; o número 2 , na coluna da máquina que executa a segunda opcração; c assim sucessivamentc); c

5) identificar todos os conjuntos de peças que apresentarem a mesma scqüiencia de operações.

Com este procedimento, ficam simultancamente definidos os equipamentos $\mathrm{c}$ as máquinas que constituirão cada célula de maunuatura e os conjuntos de peças, ou sẹja, as famílias, que scrão processadas cm cada célula.

\section{Critérios Preliminares para Constituição da Célula por Processo}

O que motiva o layout cclular por processo é o aproveitamento da espera do operador durante o tempo automático da máquina - atribui-sc a clc outra atividade, geralmente outra máquina. Desta forma, o ganho de produtividade do homem é significativo, como já mencionado.

Para constituir uma célula por processo, pode-sc, inicialmentc, atribuir ao operador várias máquinas que tenham ciclo automático, sem considerar o produto. Assim, um grupo de fresadoras ou de coquilhadciras ou de sopradoras de macho ou de tornos automáticos ou de tornos revólveres ou de centros de usinagem pode 
constituir uma cćlula com um único operador. Já para prensas, tornos universais c furadciras manuais, cssc conccito não se aplica porque míquinas desic tipo exigem dedicação cxclusiva do operador por não terem ciclo automático (ou, quando cxistc, ć de pequena duração); não havendo espera do operador, ganho de produtividade só advirá de outros fatores. A mesma conclusão scrve para trabalhos $\mathrm{cm}$ bancada - não há csperas do opcrador. Mas, combinar uma bateria de furadeiras pneumáticas com furadeiras de bancada ou rosqueadciras com furadciras manuais ou furadeiras pncumáticas com rosquadeiras é solução, pois a furadcira pncumática $\mathrm{c}$ a rosqueadcira lêm ciclo automático.

Simplesmente agrupar máquilas que tcnham ciclo automático. sem levar $\mathrm{cm}$ consideração os produtos, não ć bom critério, não obstantc propiciar aumento da produtividade. Para melhorar a solução, c quiçá otimizá-la, ć necessário também levar em consideração o produlo.

A fim de introduzir o produto no processo de constituição da célula por processo, é preciso decidir sobre a quantidade de produtos que scrá processada simultancamente pela célula: um só ou mais de um modclo. É a decisão dominante. Estes dois casos scrĩo analisados nas duas próximas subseções.

\section{Critérios para Escolha dos Modelos a Serem Fabricados Concomitantemente na Célula por Processo}

Fabricar simultancamentc, ma célula de manufatura por processo, mais de $u m$ modelo (geralmente dois, raramente mais de três) evige estudo relativamente longo para decidir quais os pares ou os ternos de modelos, de forma a minimizar o tempo de cspera do homem sem acarretar esperas cxcessivas da máquina (no trabalho homem-máquina, um deles quase sempre esperara o outro, como será discutido nas considerações finais).

Assim, os critérios para escolher os pares ou ternos de modelos a serem processados simultancamente numa célula por processo são:

1) a quantidade de peças a ser fabricada de um modelo deve ser próxima à dos outros modelos que constituirão o par ou o terno. pois se for bastante diferente. o lote de um modelo será concluido muito antes do lote do outro modelo, acarretando, ma fase final, a fabricação de apenas um modelo ocupando uma máquina, o que inviabiliza o aproveitamento do tempo ocioso do operador, c a célula deixari de funcionar como tal:

2) os prazos de entrega dos modelos a screm produzidos concomitantementc deverĩo ser próximos, de forma a reduzir o tempo de estocagem daquele produto acabado cujo prazo de entrega seja mais longo;

3) o ciclo de operaçĩo dos modelos que constiluirão o par ou o terno nas máquinas da célula deve ser próximo, a fim de evitar que as máquinas de menor ciclo fiquem esperando excessivamente a de maior ciclo;

4) a soma do tempo de atividade do operador nas diversas máquinas da célula deveri ser próxima ao tempo do ciclo de opcração dos modelos que constiluirão o 
par ou tcrno, de forma que o tempo de espera do homem $\mathrm{cm}$ relação às máquinas ou o tempo de cspera das máquinas $\mathrm{cm}$ relação ao homem seja mínimo; c

5) na célula que contiver uma máquina com alta carga de trabalho, os pares ou ternos de modelos deverão ter ciclos cujas durações não acarretcm esperas nessa máquina.

Formar uma célula por processo, ou sẹa, decidir quais máquinas a comporão $\mathrm{c}$ quais os pares ou os ternos de modelos que scrão fabricados concomitantementc, de forma a atender os três últimos critćrios, $\dot{\mathrm{c}}$ um processo trabalhoso, cxige muito tempo de estudo, mas perfeitamente factivel pois são inúmeras as soluções viáveis. Entrctanto, conciliar os trĉs últimos crilérios, que se refercm à duração do ciclo de opcração, com os dois primciros, quantidade c prazo, não ć larefa fácil, pois, se a cmpresa pode ter domínio sobre a variável prazo, não o $1 \mathrm{~cm}$ sobre a variável quantidade. Nesta situaçĩo, a programação da produção fica mais complexa, uma vez que, alćm das limitações nomuais, outras restrições decorrentes dos cinco critérios precisam ser consideradas. Com o propósito de simplificar a programação, o PCP deve lançar em produção sempre juntos os pares oul os ternos de produtos pré-definidos.

Em algumas situações, a determinação de quais máquimas formarão uma célula $\mathrm{c}$ de quais pares ou temos de produtos scrão produzidos simultancamente torna-sc ainda mais complcxa, pois surgem outras restrições. É o caso da fundição de peças cm coquilha. O tempo de solidificação da peça fundida, que corresponde ao tempo automático de uma máquina operatriz, ć, $\mathrm{cm}$ média, pouco maior do que a melade do ciclo de produção de uma peça, de forma que cada fundidor pode operar duas coquilhadeiras, mas não três. Com este dado, define-sc que a célula será composta por um fundidor e duas coquilhadeiras. Resta, pois, decidir quais serão os pares de produlos a serem fundidos concomitantemente, que no caso significa decidir quais coquillas, pois uma peça sempre usa a mesma coquilla; mas, numa coquilhadeira montam-se diversas coquilhas.

Para csla decisão, no caso usado como ilustração - uma fundição -, aos cinco critérios cslabclecidos, somam-sc mais três:

1) As coquilhadciras são máquinas relativamente leves pois precisam ser deslocadas com muita frequiência - uma cmpilhadeira as coloca na linha de produção quando forcm ser utilizadas $\mathrm{c}$ as remove para o depósito após o término de scu programa de produção. (As coquilladeiras de porte maior são fixas no piso). Elas são colocadas sempre na mesma posição $\mathrm{cm}$ relação à rede de gás, de ólco lidráulico e de ar comprimido uma vez que suas tomadas para engate dessas utilidades ficam de um único lado. Ora, para compor uma célula, duas coquilhadeiras precisam ficar face a face, com o fundidor cutre clas, o que significa que, para formar um par, ć necessário juntar uma máquima com tomadas à dircita com outra cujas tomadas cstão à csquerda. É uma restrição que só desaparcecrá quando lodas coquilladeiras puderem ser ligadas à dircita c à csquerda. 
2) Como algumas coquilhas só podem ser montadas $\mathrm{mum}$ detcrminado tipo de coquilhadeira, sc existir apenas uma desse lipo, não é possível combinar entre si as coquilhas cativas dessa coquilhadeira para constituir a célula funcional.

3) Como a fundição trabalha 'com diversas ligas de metal, que ficam $\mathrm{cm}$ fornos de espera na coquilharia, só podem compor um par aquelas peças fundidas na mesma liga, uma vez que um forno de cspera abastece várias coquilhas.

Como se depreende do exposto, a decisão de quais pares de peças scrão fundidas numa célula de manufatura funcional está sujeila a oito restrições. É pois um processo trabalhoso, não obstantc a mobilidade das coquilhadciras; mas compensador - num caso real, o aumento tcórico de produtividade do homem cra de $89 \%$, valor que caia para a casa dos $60 \%$ devido à necessidade de períodos de repouso para o fundidor $\mathrm{c}$ à dificuldade de se conseguir pôr $\mathrm{cm}$ produção todas as vezes o par ótimo, conforme relatado nas considerações finais.

\section{Critérios para Constituição da Célula por Processo Fabricando um só Produto de Cada Vez}

Como mencionado anteriormente, pam definir a configuração da célula de manufatura por processo ć preciso decidir sobre a quantidade de produtos que scrá processada concomitantemente na célula: um ou mais de um modclo. Na subseção antcrior, foram definidos critćrios para o caso de mais de um modelo; nesta, scrá discutido o caso de a célula processar apenas um produto de cada vez.

Fabricar um produto de cada vez. significa destinar cada máquina da célula a uma opcração do processo de fabricação desse prodilto.

Decidir quais máquinas constituirão uma cćlula funcional para processar um único produto de cada vez ć mais simples do que o caso de fabricar mais de $\mathbf{~ u m}$ produto simultaneamente, porque os dois primeiros dos cinco critćrios, aprescntados na subseção anterior, desaparecem: a quantidade $\mathrm{c}$ o prazo de entrega do produto são os mesmos. O terceiro, quanto e quinto critćrios, com pequenas alterações, precisam ser obcdecidos:

3) o ciclo de trabalho de cada operação cxeculada na célula deverá ser próximo ao das outras opcraçõcs, a fim de reduzir o tempo cm que as máquinas de menor ciclo ficam csperando a de maior ciclo;

4) a soma do tempo de atividade do operador nas diversas máquinas da célula deverí ser próxima ao tempo do ciclo das demais operações, de forma que o tempo de espera do homem $\mathrm{cm}$ relação às máquinas ou o tcmpo de cspera das máquinas cm relação ao homem seja mínimo; c

5) as máquinas com alta carga de trabalho precisam cstar cm células definidas de forma a que nem o operador nem as outras máquinas int roduzam csperas no seu ciclo de trabalho.

A célula por processo fabricando 1 III único produto de cada vez assemelha-se à cćlula por produto - corresponde à partição da cćlula por produto em subcélulas 
contendo apenas máquinas do mesmo tipo. Lembre-sc que a razão fundamental da cćlula por processo ć a desobrigatoricdade da cxistência do operador multifuncional, 0 que torna imediala a sua implantação.

\section{Um Caso Real: As Células por Processo de uma Usinagem}

Ilustrar a cxposição com um caso real sempre auxilia o entendimento.

A seção de usinagem de una fundição foi organizada em células de manufatura por processo que fabricavam uma única péça de cada ve\%. Como sc notará, mesclou-sc. cm algumas células, o conceito de cćlula por processo com o de célula por produto, pois foram colocadas outras máquinas diferentes, mas de fácil operação, junto às máquinas principais.

As fresadoras passaram a formar várias células de um único opcrador, algumas com duas ou três fresadoras c uma bancada para pequenos serviços, outras com duas fresadoras, duas ou três furadeiras de bancada c uma bancada. Tomou-se o cuidado de atribuir ao fresador apenas operaçõcs simples que não cxigiam trcinamento, como rebarbar peças com csmcrilhadeira penumática ou furí-las $\mathrm{cm}$ furadciras de bancada.

As furadeiras pncumáticas $c$ as de bancada fomaram várias células de um único operador, algumas com duas ou três batcrias de furadciras pneumáticas. outras com uma batcria de furadeiras pneumáticas c algumas furadciras de bancada. Em ambos os casos com a rinalidade de aproveitar o ciclo automático das furadeiras pncumáticas. Foram constituidas algumas células de um operador contendo várias furadciras de bancida, cuja finalidade não cra aproveitar o ciclo automático (incxistcnte nessas máquinas) mas sim reduzir o manuscio de peças. (Quando as pecas são processadas em uma operação de cada vez, 0 operário apanha a peça no cesto. cxecuta a operação $\mathrm{c}$ a coloca $\mathrm{em}$ outro cesto: quando são ralizadas várias opcraçõcs sequïenciais, o operário apanha a peça no cesto, cxecula as várias operaçõcs c a coloca $\mathrm{cm}$ outro cesto, climinando muitos movimentos de apanhar a peça e de colocí-la no cesto)

O mesmo conceito foi aplicado is rosqueadciras, que passaram a constituir diversas células funcionais, algumas com rosqucadeiras automáticas mais rosqucadciras manuais, outras com rosqueadciras manuais mais furadciras de bancada com o objelivo de reduzir o manuscio de peças.

Já os tornos, os aparclhos de balanceamento $c$ as bancadas para montagem c para serviços manuais não foram organizadas em células pela razão de as atividades aí rcalizadas ocuparem quasc que integralmente o tempo do operador, ou scja, não havia espera do homem durante o ciclo de trabalho.

A tabela 3 mostra as operações realizadas numa célula de fresadoras c noutra de furadeiras, comparando o tempo das operações individuais com o tempo da célula. Para cxccutar individualmente as 
scis opcrações que passaram a ser realizadas na célula das fresadoras, gastavam-se anteriormente 11,48 minutos; na organização celular, o operador conseguia cxccutar as últimas cinco operações durante o tcmpo-automático da primeira - portanto, o tempo das scis operações ficou reduzido ao tempo da primeira (5,50 minutos). propiciando $\mathrm{um}$ aumento de produtividade do homem de $109 \%$.

Na cćlula das furadeiras, constituída por duas pneumálicas c uma de bancada, o homem Irabalhava 0,80 minuto cm cada pneumática (para um ciclo de 2,(0) minutos) c 1,10 minulo na furadeira de bancada. $O$ tempo total de 5,10 minutos caiu para 2,70 minutos devido à organização celular, gerando um aumento de produtividade do homeill de $89 \%$.
A produtividade média dessa seção de usinagem era $2,69 \mathrm{~kg} / \mathrm{homem-hora.} \mathrm{(Parece}$ estranho medir a produção de peças usinadas pelo seu peso. Mas, como uma fundição avalia cm peso o scu volume de produção, essa unidade acabou por contaminar a produção da usinagem. Entretanto, ć boa medida desde que o mix de produtos não sofra variação significativa de umı mês para outro - c, de falo, o mix de produlos, no caso, não variava signilicantemente). A implantação das células de manufatura funcional c de outras medidas propostas nesta sćric de artigos tinha por meta clcvar a produtividade para $5,0 \mathrm{~kg} /$ homem-hora, um aumento de $86 \%$. Para satisfação de todos, em dois meses, a produlividade alcançou a média de 7,0 $\mathrm{kg} /$ homem-hora, um cxpressivo aumento dc $160 \%$ !

\begin{tabular}{|c|c|c|c|}
\hline DESCRICȦO DAS OPERACCESS & MAQUUINA & $\begin{array}{l}\text { TEMPOS } \\
\text { INDIVIDUAIS } \\
\text { (MIN) }\end{array}$ & $\begin{array}{l}\text { TEMPONA } \\
\text { CËLULA } \\
\text { (MIN) }\end{array}$ \\
\hline $\begin{array}{l}\text { CÉLULA DE FRF:SADORAS } \\
\text { 1. Frcsar flange } \\
\text { 2. Frcsar } 4 \text { bolachas } 160 \mathrm{~mm} \\
\text { 3. Rebarbar flange e } 4 \text { bolachas } \\
\text { 4. Furar } 25 \mathrm{~mm} \\
\text { 5. Escariar } 25 \mathrm{~mm} \\
\text { 6. Rebaixar bolacha } 120 \mathrm{~mm} \\
\text { TEMPO TOTAL. }\end{array}$ & $\begin{array}{c}\text { FR-1 } \\
\text { FR-2 } \\
\text { B } \\
\text { FB-1 } \\
\text { FH-2 } \\
\text { FB-3 }\end{array}$ & $\begin{array}{c}5,5 \\
2,13 \\
1,50 \\
0,70 \\
0,37 \\
1,28 \\
11,48 \\
\end{array}$ & 5,50 \\
\hline $\begin{array}{l}\text { CÉLULA DE FURADEIRAS } \\
\text { 1. Furar } 12 \times 10 \mathrm{~mm}-10 \times 8 \mathrm{~mm} 4 \times 6 \mathrm{~mm} \\
\text { 2. Furar } 8 \times 10 \mathrm{~mm}-3 \times 8 \mathrm{~mm} \\
\text { 3. Rebaixa } 20 \times 10 \mathrm{~mm} \\
\text { TEMPO TOTAL. }\end{array}$ & $\begin{array}{l}F^{P}-1 \\
F P-2 \\
F B-4\end{array}$ & $\begin{array}{l}2.00 \\
2,00 \\
1,10 \\
5.10\end{array}$ & 2.70 \\
\hline
\end{tabular}

Tabela 3 - Comparação entre Operação Individual c Operação Celular Funcional 


\section{Duas Considerações Finais}

\section{Célula de Manufatura versis Enriquecimento de Funções}

Sc o objetivo for aumentar a produtividade do homem, a solução celular ć, na grande maioria dos casos, melhor do que o cnriquecimento de função.

Esludavam-se numa fundição duas allernativas para aprovcitar o tempo durante o qual o fundidor ficava csperando a solidificação da peça: dar acabamento nos machos ou operar duas coquilhadeiras. A primcira alternaliva consistiria $\mathrm{cm}$ transferir para o fundidor uma operação que cra exccutada na macharia por um macheiro. A scgunda résullaria numa célula de manufatura por processo constituida por duas coquilhadeiras $\mathrm{e} \mathrm{um}$ fundidor.

Simuladas cssas duas altcrnativas para as principais peças, responsiveis por mais da melade do volume de produção em peso, apurou-se que, se ao fundidor fosse atribuída a opcração de dar acabameṇto no macho. o aumento médio de sua produtividade scria de $30 \%$; c que. se a cle rosse alribuida uma segunda coquilhadeira, com pares de peças adequadamente escollidos. o aumento scria de $89 \%$.

Opcrando duas coquilhadciras, o fundidor ficaria mais icmpo cxposto i temperatura clevada. pois. quando opera apenas uma. distancia-se da coquilha durante a solidificaçĩo da
peça.Impunha-sc,cntão, darumpcriodode repouso de 10 minutos acada hora e meiae aumentar a reidratação salina para compensara maior perda de sais minerais causadapelamaiorsudorese.Paraajornada de8horas,scriamnecessáriost rêsperíodos de repouso, uma vez que a parada para refcição serve também como periodo de repouso, que representariam uma diminuição de $6,7 \%$ no tempo útil de 450 minutos do lurno. Além desta perda, cra plausívelsuporumaoutra, daordemde $8 \%$, calusada pela dificuldade de se conseguir todasasvezcsoparmaisadequadodepcças a fundir. Mcsmo com cstas duas perdas, o aumento da produtividade gerado pela operação de duas coquilhadeiras scria superiora $60 \%$.

Estc caso, bastante clucidativo, acrescido de diversos outros, permitc-nos gencralizar: na maioria das vezes, a célula de manufatura é mais potente do que o curiquecimento de funçôes para aumentar a produtividade do homem.

\section{"Máquina Não Pode Parar"}

Estão arraigados na mente do pessoal da industria brasilcira dois conccitos: "máquina não pode parar" c "nossa mão-de-obra ć barala".

Esses dois conccitos, atuando durante anos. passando de geração $\mathrm{cm}$ geração. transformaram-se cm verdades absolutas, inquestionáveis c dogmáticas. Devido a cles, toda atenção do gerente c do supervisor de produção sempre esteve voltada para a máquina, ficando o trabalho do operário relegado a segundo plano. 
Todos procuraram, cntão, olimizar o ciclo-máquina, o que acarrcta cspcras, às vezes altissimas, do operador.

Ora, a análise das empresas, industriais bem-sucedidas demonstra que a produtividade do homem ć mais importante do que a da máquina, ou pelo menos igual. $\mathrm{Na}$ indústria japonesa. hoje clevada à condição de paradigma mundial, a produtividade do homem ć prevalentc à da máquina.

Deve-sc, pois, procurar otimizar o ciclo-homem. mesmo que cm detrimento do ciclo-máquina, ou seja, mesmo que à custa da introdução de esperas no ciclo de trabalho da máquina.

Isto ocorre, quase sempre, numa célula de manufatura. Veja-se o caso de um machiciro operando duas sopradoras de macho shell. O aumento da produtividade do macheiro foi de $52 \%$, significando que as duas máquinas passaram a ter produção num índice 152. Quando uma máquina ć operada por um homem, seu indice ć $1(\%)$; duas máquinas, 200). Portanto, as duas sopradoras, quando opcradas por um úmico machciro, tiveram sua produção reduzida do indice 200 para o índice 152; ou seja, perderam. cm mćdia, $24 \%$ de produçĩo c portanto $24 \%$ de produlividade (a máquina cujo ciclo de produção é mais longo $\mathrm{tcm}$ perda menor, enquanto a de ciclo mais curlo, perda maior). No caso de um fundidor opcrando duas coquilhadeiras. citado no item anterior. cm contrapartida ao aumento de $60 \%$ na produtividade do homem, houve uma queda de $20 \%$ na produlividade da máquina.
Ora, se o aumento da produtividade do operador quase scmpre acarreta a diminuição da da máquina, a produção de cada máquina scrá menor. Assim, para manter o mesmo volume de produção, mais horas-máquinas serão necessárias, o que significa que precisa haver disponibilidade de máquinas; em outras palavras, precisa haver ociosidade de máquinas.

A indústria brasileira de manufatura possui. atualmente, disponibilidade de máquinas, sendo raras as cxceções. Não possui ociosidade de pessoal, pois csie cstá dimensionado para atender à demanda atual, pois a prática correntc é demitir quando as vendas cacm $\mathrm{c}$ cont ratar quando sobcm.

Nas fábricas que trabalham $\mathrm{cm}$ um ou dois turnos, $c$ são a grande maioria na indústria de manufatura, se não houver ociosidade de máquinas, suficiente para suportar as horas-máquinas adicionais necessárias para compensar a perda de produtividade acarretada pela célula de manufatura, pode-se adotar uma solução simples: criar mais um-lurno de trabalho c relocar parte dos opcrários, dos mestres c dos supervisores para esse novo turno

Esta solução representa, cm última instância, uma redistribuição da ociosidade das máquinas. Sc a fábrica traballa dois lurnos de oito horas por dia, as máquinas ficam paradas durante oito horas todo dia. A solução aqui proposta - otimizar o ciclo-homem mesmo que pela introdução de esperas no ciclo da máquina comesponde a distribuir, alo longo das $2+$ 
horas do dia, essa grande cspera concentrada $\mathrm{cm}$ oito horas, dando um pouco de espera dentro de cala ciclo de trabalho da máquina. Como se vê. a solução é perfeitamente viável, não obstante introduzir alguns custos indirctos, como o funcionamento $\mathrm{cm}$ mais um turno do restaurante, do ambulatório, da manutenção, do almoxarifado. Mas, o aumento de produtividade obtido proporciona cconomias que compcissam com grande margem csses custos indirctos adicionais, atć porque csses sctores opcram no nivel mínimo durantc o turno da madrugada.

Se a fábrica já traballa nos três turnos, a ociosidade das máquinas precisa scr increntc à capacidade instalada, uma vez que a citada distribuição das oito horas do tercciro turno, ao longo das 24 horas, não ć possivel.

Com a argumentação aprescntada, esperamos ter desmistificado o conceito de que a máquina não pode parar: se for para aumentar a produtividade do homem, a máquina pode parar (a não ser quando a máquina estiver totalmente carregada on for de custo operacional proporcional mente clcvado).

\section{Referências Bibliográficas}

BEZERRA. J. C. Simples...mente Just-in-Timc. São Paulo. IMAM. 1990.

CONTADOR, J. C. Tipologia da
Célula de Manufatura. Scgundo Simpósio de Ciĉncias Exalas c Engcnharias da Universidade Estadual Paulista, Campos do Jordão, de\%. 1991.

HALL, R. W. Excelcencia na Manufatura. São Paulo, IMAM, 1988.

HILLESHEIM, S. W. \& COSMO, J. R GSA - Grupos Semi-autônomos. Rio de Janciro, COP Editora, 1988.

IMAM Produtividade c Qualidade no Piso de Fábrica - São Paulo. Instituto de Movimentação e Armazenagem de Matcriais, 1989

KAPSTEIN, J. \& HOERR, J. Inovações na Linha de Montagem. Business Weck. In: Gazela Mercantil, São Paulo, 9 sct. 89.

MONDEN, Y. Sistema Toyota de Produção. São Paulo, IMAM, 1984.

MOURA, R. A. Kanban. São Paulo, IMAM, 1989.

OLIVÉRIO, J. L. A Manuratura Celular. Scgundo Scminário de Técnicas Japonesas promovido pelo IMAM. São Paulo, IMAM, 1984.

SCHONBERGER, R. J. Técnicas Industriais Japoncsas. São Paulo, Pioncira, 1984.

YOSHINAGA. C. Qualidade Total. São Paulo, 1988. 